\title{
Two cases of agenesis of the dorsal pancreas and a review of the literature
}

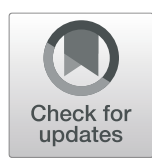

Wentong Mei ${ }^{1,2}$, Feng Cao ${ }^{1,2}$ and Fei $\mathrm{Li}^{1,2^{*}}$

\begin{abstract}
Background: Agenesis of the dorsal pancreas (ADP) is a very rare disease with no specific symptoms, and the pathogenesis is not clear. Some patients will be accompanied by other diseases, such as pancreatic tumor or pancreatitis. But most cases are very atypical and difficult to distinguish. Some syndromes of pancreatic exocrine insufficiency are common in patients with ADP. Here, we report two cases of ADP and summarize the clinical features, diagnosis, and treatment of ADP.

Case presentation: Case A is a 65-year-old Chinese woman who presented with abdominal pain accompanied by nausea, bloating and acid reflux. The enhanced abdominal $C T$ scan found nothing meaningful except the absence of the body and tail of the pancreas. The diagnosis was considered as gastrointestinal dysfunction cause by exocrine pancreatic insufficiency and recovered after symptomatic treatment. Case B is a 61-year-old Chinese woman who presented with abdominal pain accompanied by fever, vomiting and bloating. The abdominal CT showed multiple stones in the gallbladder, and the body and tail of the patient's pancreas were absent. She was diagnosed with cholelithiasis and recovered after laparoscopic cholecystectomy.

Conclusion: Agenesis of the dorsal pancreas (ADP) is a rare congenital disease with an unclear pathogenesis that presents multiple symptoms. It should be considered when the patients have non-specific, persistent and unexplained symptoms such as bloating or uncontrolled blood sugar. Imaging examination is helpful for diagnosis. And it does not require surgical intervention unless it accompanies other diseases, EPI need to be considered when the non-specific gastrointestinal symptoms appear.
\end{abstract}

Keywords: Agenesis of the dorsal pancreas (ADP), Pancreatic disease, Pancreatic dysplasia, Case report

\section{Background}

Agenesis of the dorsal pancreas (ADP) is a very rare anatomical variation of the pancreas. It is characterized by the partial or total loss of the body and tail of the pancreas. The disease has no specific clinical symptoms but may accompany pancreatic secretion insufficiency and other pancreatic diseases. Most cases were discovered by chance. This paper reports two cases of ADP,

\footnotetext{
* Correspondence: feili35@163.com

'Department of General Surgery, Xuanwu Hospital, Capital Medical University, No.45 Changchun Street, Beijing 100053, China

${ }^{2}$ Clinical Center for Acute Pancreatitis, Capital Medical University, Beijing, China
}

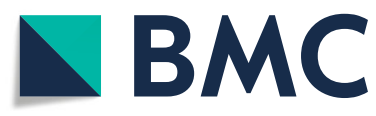

(0) The Author(s). 2020 Open Access This article is licensed under a Creative Commons Attribution 4.0 International License, which permits use, sharing, adaptation, distribution and reproduction in any medium or format, as long as you give appropriate credit to the original author(s) and the source, provide a link to the Creative Commons licence, and indicate if changes were made. The images or other third party material in this article are included in the article's Creative Commons. licence, unless indicated otherwise in a credit line to the material. If material is not included in the article's Creative Commons licence and your intended use is not permitted by statutory regulation or exceeds the permitted use, you will need to obtain permission directly from the copyright holder. To view a copy of this licence, visit http://creativecommons.org/licenses/by/4.0/. The Creative Commons Public Domain Dedication waiver (http://creativecommons.org/publicdomain/zero/1.0/) applies to the data made available in this article, unless otherwise stated in a credit line to the data.
A 65-year-old Chinese woman presented with a history of abdominal pain for 3 days. The patient developed paroxysmal abdominal pain in the past 3 days, accompanied by nausea, bloating and acid regurgitation. The pain was limited to the middle and upper abdomen, and anal exhaust and bowel movements were normal. The symptom did not become aggravated during the 3 days. She denied the symptoms of steatorrhea. The patient has had type 2 diabetes for more than 20 years and used a drug regimen

\section{Case A}


to control the DM, but the patient complained that her fasting blood glucose was still poorly controlled. She had no other diseases. Her family medical history was unremarkable.

No positive signs were found in the physical examination. The results of the hematological examinations were normal. Only the blood sugar $(11.7 \mathrm{mmol} / \mathrm{L})$ and triglycerides $(4.3 \mathrm{mmol} / \mathrm{L})$ were abnormal in the blood biochemical examination, and no signs of infection were found. No abnormal results were observed from the electronic gastroscopy and electronic colonoscopy, which were performed 2 months ago. An enhanced abdominal CT scan revealed slightly increased gastrointestinal contents and no signs of acute abdominal (obstruction, perforation, etc.) or celiac vascular disease but found that the patient did not have the body and tail of the pancreas (Fig. 1a-b).

So the preoperative diagnosis is gastrointestinal dysfunction, agenesis of the dorsal pancreas, and pancreatic exocrine insufficiency were not excluded. Mosapride and trimebutine were used to improve gastrointestinal function, and $0.6 \mathrm{~g}$ pancreatin enteric-coated capsules were given to the patient before each meal continuously to supplement her pancreatic exocrine function. And Intermediate effect insulin were used to help control the fasting blood glucose.

The patient returned to the gastrointestinal surgery clinic 1 week later, complaining that although the symptoms were significantly relieved, but there was still mild postprandial bloating. Here fasting blood glucose fluctuates from approximately $5-8 \mathrm{mmol} / \mathrm{L}$. The physician continued to give the patient the above medications.

\section{Case B}

A 61-year-old Chinese woman presented with a history of upper right abdominal cramping with vomiting and fever for $10 \mathrm{~h}$. The patient developed the above symptoms after eating greasy food $10 \mathrm{~h}$ ago; she vomited her stomach contents and bile repeatedly, but did not experience hematemesis. Fever occurred after the abdominal pain, and the highest body temperature was $38.8^{\circ} \mathrm{C}$. She did not present with chills, jaundice, constipation or diarrhea. Apart from these observations, the patient had a history of intermittent bloating after meals for at least 20 years, and she denied the symptoms of steatorrhea. The patient has had type 2 diabetes for 12 years, and metformin and glimepiride were used to control the DM; her fasting blood sugar level fluctuates from approximately $7-10 \mathrm{mmol} / \mathrm{L}$. She also has congenital scoliosis. Her family medical history was unremarkable.

The patient's body temperature was $38.9{ }^{\circ} \mathrm{C}$, and her BMI was $32 \mathrm{~kg} / \mathrm{m}^{2}$. The physical examination revealed mild abdominal muscle tension, tenderness in the right upper quadrant, and positive Murphy's sign. The hematological examinations showed a high white blood cell count $\left(14.4^{*} 10^{\wedge} 9 / \mathrm{L}\right)$ and an elevated neutrophil percentage (87.7\%). The blood biochemistry tests showed high blood sugar $(12.1 \mathrm{mmol} / \mathrm{L})$, low $\mathrm{K}^{+}(2.9 \mathrm{mmol} / \mathrm{L})$ and low total cholesterol levels $(6.2 \mathrm{mmol} / \mathrm{L})$. The abdominal CT including coronal reconstruction and sagittal reconstruction image showed multiple stones in the gallbladder, and the gallbladder wall was rough and had mild edema (Fig. 2a). The body and tail of the patient's pancreas were absent; in the area where the tail of the pancreas should be, we only observed blood vessels of the spleen (Fig. 2b-i). Since the patient had no evidence of bile duct stones, MRCP was not performed in the emergency department.

So the preoperative diagnosis is acute cholecystitis, cholelithiasis, agenesis of the dorsal pancreas, and pancreatic exocrine insufficiency were not excluded. We gave the patient gastric decompression. Cefminox were used to control the infection, and magnesium sulfate was used as a cholagogue. In addition, to relieve her symptoms, we used anisodamine, metoclopramide and famotidine. Rehydration therapy and potassium supplementation were conducted simultaneously. After the
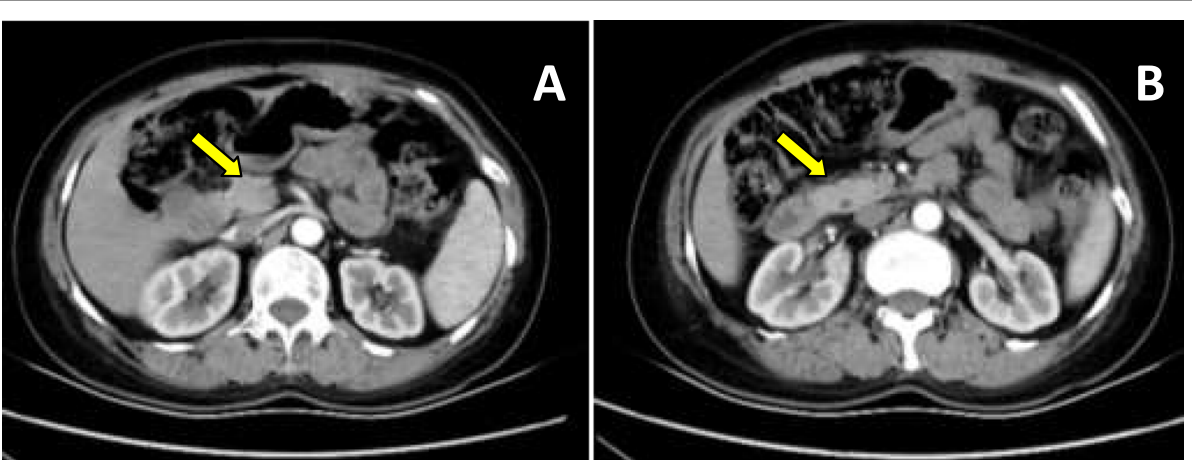

Fig. $1 \mathbf{a}$ and $\mathbf{b}$ Axial arterial phase $C T$ image showing the absence of the pancreatic body and tail, without pancreatitis and pancreatic duct dilatation. The arrow show the pancreatic head 


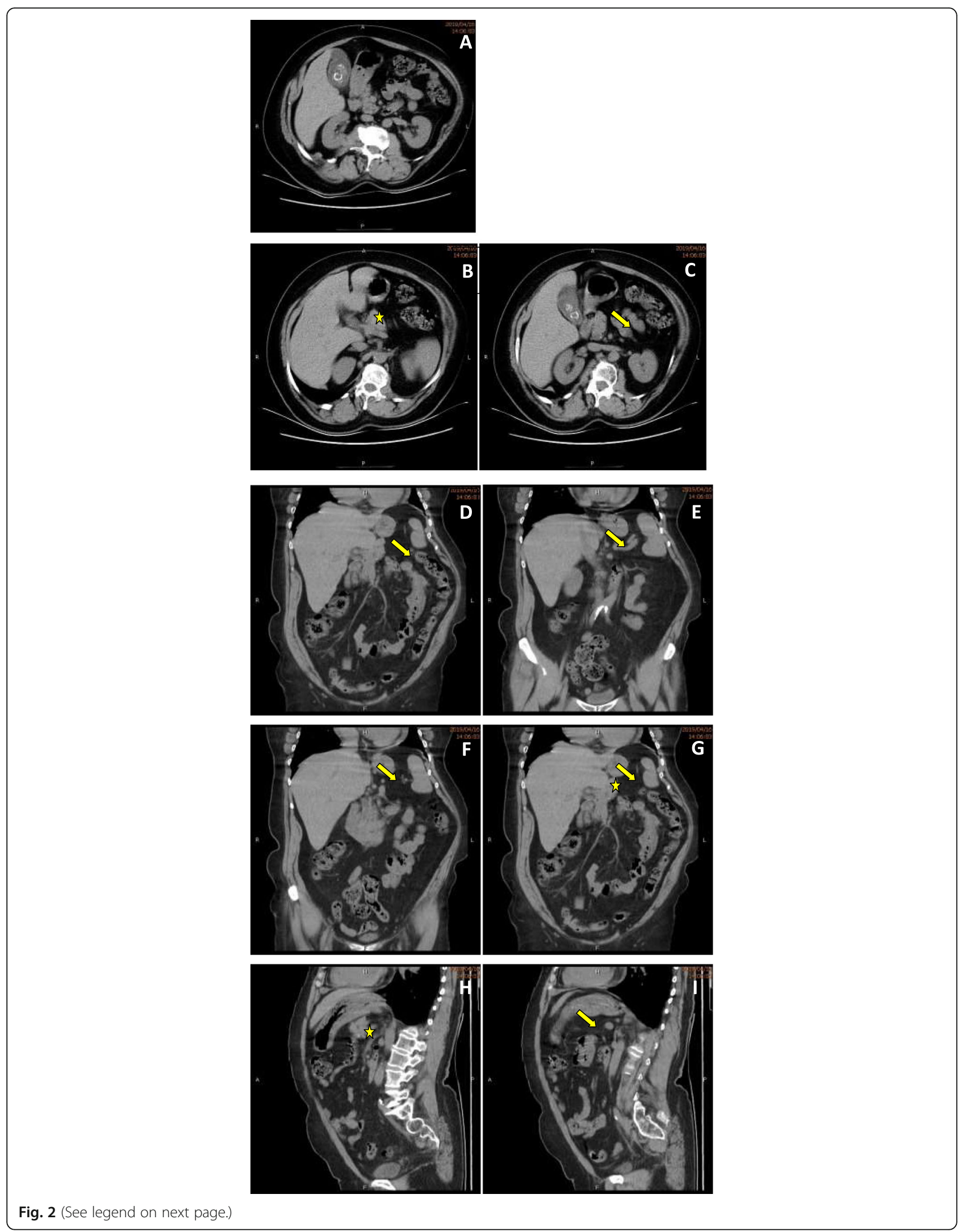


(See figure on previous page.)

Fig. 2 a Abdominal CT image shows the stones in the gallbladder and the inflamed gallbladder. b-i Abdominal CT image including coronal reconstruction ( $\mathbf{d}-\mathbf{f})$ and sagittal reconstruction (h and $\mathbf{i})$ image shows the head of the pancreas without the body and tail. The star shows the pancreas head, the arrow indicates the area of the body and tail of the pancreas and now only the retinal tissue and the blood vessels of the

spleen is there

patient recovered from the acute stage, she underwent laparoscopic cholecystectomy; $1.8 \mathrm{~g}$ pancreatin entericcoated capsules were given per day continuously to relieve the symptoms of pancreatic exocrine function.

The patient's symptoms completely improved after the drug regimen in the acute stage, and she had no abdominal pain after the LC surgery. After 3 weeks of pancreatic enzyme replacement therapy, she said that her symptoms of bloating after meals significantly improved.

\section{Discussion and conclusion}

The pancreas is formed by the ventral and dorsal pancreatic buds. Most of the pancreas is derived from the dorsal pancreas, which differentiates into the body and tail of the pancreas, part of pancreatic head, accessory pancreatic duct and distal part of the pancreatic duct [1].

Agenesis of the dorsal pancreas (ADP) is a rare anatomical variation of the pancreas. It was first reported in 1911 by Schnedl, and approximately 100 cases have been published up to now [2]. ADP is characterized by the absence of the pancreatic body and tail; if only the pancreatic tail is missing, it is called partial agenesis of the dorsal pancreas. If the pancreatic body is also lacking and only the pancreatic head is present, it is known as complete agenesis of the dorsal pancreas [3]. At present, the pathogenesis of this disease is not fully understood. The HNF1B gene is known to regulate pancreatic development, some studies have found that ADP and pancreatic exocrine dysfunction are parts of the phenotype in HNF1B mutation carriers, and GATA6 gene mutations also can lead to pancreatic hypoplasia [4-6]; animal experiments have confirmed that retinaldehyde dehydrogenase 2 (Raldh2) [7] and gene H1xb9 [8] mutations can cause ADP in mice.

Most simple ADP patients have no specific symptoms. Patients can be found through imaging examinations for common abdominal symptoms such as pain or bloating. There is no evidence that ADP alone can cause abdominal pain. There were several studies that reported that ADP can be complicated by acute pancreatitis. The mechanism of which may be Oddi sphincter dysfunction, pancreatic head compensatory hypertrophy, increased pancreatic juice secretion, and pancreatic duct hypertension $[9,10]$. Because of the above mechanism, the possibility of ADP combined with chronic pancreatitis has theoretically increased. A small number of patients have been diagnosed with chronic pancreatitis due to persistent chronic abdominal pain, and ADP has been subsequently discovered [11]. Moreover, we have searched a limited number of ADP-related cases of recurrent pancreatitis. One case reported recurrent abdominal pain after drinking [12]. Amylase and lipase values did not support the diagnosis of acute pancreatitis and the symptoms was disappeared after forbearing from alcohol; Another case was also recurrent abdominal pain [13]. Endoscopy revealed that Santorini's duct was dilated and contained calculi but Wirsung's duct was nearly normal. And the junction between the two ducts was slightly narrowed. It was considered chronic pancreatitis. The patient underwent internal endoscopic sphincterotomy and the symptoms were relieved after the operation. In addition to most of the islet $\beta$ cells being located in the tail of the pancreas, patients with ADP also have diabetes due to insufficient insulin secretion, but not necessarily abdominal symptoms [14, 15]. Approximately half of these patients need insulin therapy. A young woman with ADP was reported to have asymptomatic insulin-dependent diabetes mellitus and already had severe retinal lesions at the time of presentation [15]. Other studies reported ADP combined with ampullary tumors, and the pathological types included cystic adenocarcinoma, solid pseudopapillary tumors, intraductal papillary mucinous neoplasms, neuroendocrine tumors and cholangiocarcinoma [16, 17]. Some patients with pancreatic pseudocysts were also found [18].The surgical treatment of these types of patients is no different from that for patients with normal pancreatic development, but after pancreatic head resection, due to the lack of the tail of the pancreas, postoperative pancreatic exocrine insufficiency and exogenous insulin dependence will be needed. The association between tumorigenesis and ADP is unclear, but chronic pancreatitis caused by the latter is indeed one of the risk factors for cancer. In addition, ADP associated with other organ malformations has also been reported, including polycystic kidney disease, Kartagener syndrome, multiple splenic deformities, congenital choledochal cysts and biliary atresia $[19,20]$.

The diagnosis of ADP mainly relies on imaging examinations. Schnedl supported that the loss of the accessory pancreatic duct and the absence of the tail of the pancreas are conditions for the diagnosis of complete dorsal pancreatic hypoplasia. As most ADP patients are accidentally discovered because of abdominal pain, they mainly first undergo ultrasound and CT. Ultrasound is 
affected by the gas in the intestine so it is difficult for this modality to identify the part of pancreas near the splenic vessels; thus, it is easy for ultrasound to miss the disease. CT and MRI can show the complete or partial disappearance of the pancreatic body and tail [21]. The splenic vessels are only visible in that area, and the pancreatic head could be compensated and slightly full. ERCP/MRCP can clearly show the shape of the main and accessory pancreatic ducts and has high value for identifying the complete or incomplete types of ADP $[21,22]$. The disease needs to be differentiated from pancreatic fat infiltration, chronic pancreatitis and pancreatic body and tail atrophy. According to previous literature and our experience, ADP mostly manifests as the absence of the pancreatic body and tail, the density and morphology of the remaining pancreatic head should be normal, except with compensatory enlargement of pancreatic head. Pancreatic fat infiltration have unique echo characteristics in ultrasound examination and fat signal fraction (FSF) is increased in MR image, it shows more severe signal suppression than pancreatic tissue on fat suppression imaging; While chronic pancreatitis mostly has pancreatic duct dilatation, pancreas calcification and a lower apparent diffusion coefficient (ADC) values in MR image, which means an increase in fibrosis. The full pancreatic head needs to be differentiated from pancreatic head tumor and pancreatitis. By observing the peripancreatic fat gap, the presence of calcifications and enlarged lymph nodes can help to confirm the diagnosis.

There is no special treatment for ADP itself, but sometimes it is necessary to treat the accompanying disease. In case A, we did not see clear positive signs during the physical examination, and no new observations were found in the auxiliary examination, but the patient had obvious gastrointestinal symptoms. Therefore, we consider that this is a functional disease. The symptoms of patients are significantly improved after taking pancreatin enteric-coated capsules, which suggests that ADP may cause patients to have symptoms related to exocrine pancreatic insufficiency(EPI). Such cases are very rare in previous literature reports $[23,24]$. Combining our case and previous reports, pancreatin enteric-coated capsules is helpful to relieve symptoms. The patient in Case B also has persistent symptoms of EPI, but we are more concerned about her suffering from acute cholecystitis with gallstones and ADP. According to previous studies, such case are also rare. We try to demonstrate that even in the presence of ADP, many symptoms may not be related to the disease via these cases' study, and no special treatment of ADP is needed in such circumstances. In our cases, the patient has diabetes, which may be related to the loss of islet cells on the dorsal pancreas, so exogenous insulin can be considered in cases where the drug controls poor blood glucose. For those who need surgery, we believe that in addition to performing the aforementioned differential diagnosis to clarify the surgical indications, it is necessary to identify the presence of other anatomical variations, including ADP, in the surgical field for the intraoperative strategy. However, if pancreatectomy is required, the volume of the pancreas remaining after surgery should be considered.

These two patients ADP had nonspecific symptoms and were accidentally discovered, and both had bloating and diabetes, which may be related to ADP. Some tests to diagnose pancreatic exocrine insufficiency may be useful. It is regrettable that our hospital has not carried out relevant tests, so this part of the data is not complete. However, since the patients' illnesses were not related to the pancreas and bile duct, no MRCP test was performed, and the state of the pancreatic duct could not be identified. Therefore, we believe that if ADP patients are sporadically found and do not have pancreas-related symptoms, from the perspective of health economics, whether further examinations are needed to determine the type of ADP remains to be discussed. After all, there is no special treatment for this disease.

In summary, $\mathrm{ADP}$ is a rare type of autosomal genetic disease. Non-specific, persistent and unexplained symptoms such as bloating or uncontrolled blood sugar may be associated with this disease. Imaging examination is helpful for diagnosis. Simple ADP does not require special treatment; if it accompanies other diseases and doctors can make a clear diagnosis with imaging examinations, the patients can benefit from a differential diagnosis, drug treatment (such as insulin use) and surgery.

\section{Abbreviations}

ADP: Agenesis of the dorsal pancreas; MRCP: Magnetic Resonance Cholangiopancreatography

\section{Acknowledgments}

Not Applicable.

\section{Authors' contributions}

WM summarized the two cases, reviewed the literatures and write the paper; FC reviewed the literatures; FL supervised the study and reviewed the manuscript. All authors have read and approved the manuscript.

\section{Funding \\ The work of document retrieval and language proofreading is supported by Beijing Municipal Science \& Technology Commission, No. \\ Z171100001017077, Municipal Administration of Hospitals Clinical Medicine Development of Special Funding Support, No.XMLX201404.}

Availability of data and materials

All data generated or analyzed during this study are included in this published article.

Ethics approval and consent to participate

This case report did not require review by the Ethics Committee Xuanwu Hospital, Capital Medical University, Beijing, China. 


\section{Consent for publication}

Written permission for publication of the report and the individual clinical data was obtained from the patients is available for review by the editor.

\section{Competing interests}

All of the authors declare that they have no competing interests.

Received: 31 October 2019 Accepted: 27 March 2020

Published online: 06 April 2020

\section{References}

1. Fukuoka K, Ajiki T, Yamamoto M, Fujiwara H, Onoyama H, Fujita T, Katayama $\mathrm{N}$, Mizuguchi K, Ikuta H, Kuroda Y, et al. Complete agenesis of the dorsal pancreas. J Hepato-Biliary-Pancreat Surg. 1999;6(1):94-7.

2. A Cienfuegos J, Rotellar F, Salguero J, Benito A, Solorzano JL, Sangro B. Agenesis of the dorsal pancreas: systematic review of a clinical challenge. Rev Esp Enferm Dig. 2016;108(8):479-84.

3. Schnedl WJ, Reisinger EC, Schreiber F, Pieber TR, Lipp RW, Krejs GJ. Complete and partial agenesis of the dorsal pancreas within one family. Gastrointest Endosc. 1995;42(5):485-7.

4. Stanescu DE, Hughes N, Patel P, De Leon DD. A novel mutation in GATA6 causes pancreatic agenesis. Pediatr Diabetes. 2015;16(1):67-70.

5. Chao CS, McKnight KD, Cox KL, Chang AL, Kim SK, Feldman BJ. Novel GATA6 mutations in patients with pancreatic agenesis and congenital heart malformations. PLoS One. 2015;10(2):e118449.

6. Haldorsen IS, Vesterhus M, Raeder H, Jensen DK, Sovik O, Molven A, Njolstad PR. Lack of pancreatic body and tail in HNF1B mutation carriers. Diabet Med. 2008;25(7):782-7.

7. Li H, Arber S, Jessell TM, Edlund H. Selective agenesis of the dorsal pancreas in mice lacking homeobox gene HIxb9. Nat Genet. 1999;23(1):67-70.

8. Martin M, Gallego-Llamas J, Ribes V, Kedinger M, Niederreither K, Chambon P, Dolle P, Gradwohl G. Dorsal pancreas agenesis in retinoic acid-deficient Raldh2 mutant mice. Dev Biol. 2005;284(2):399-411.

9. Kumar R, Vyas K, Agrahari N, Kundu J, Jaiswal G. Complete agenesis of the dorsal pancreas: case report with imaging findings and review of the literature. Malawi Med J. 2015;27(2):73-4.

10. Jain A, Singh M, Dey S, Kaura A, Diwakar G. A rare case of complete agenesis of dorsal pancreas. Euroasian J Hepatogastroenterol. 2017;7(2): 183-4.

11. Balakrishnan V, Narayanan VA, Siyad I, Radhakrishnan L, Nair P. Agenesis of the dorsal pancreas with chronic calcific pancreatitis. Case report, review of the literature and genetic basis. JOP. 2006;7(6):651-9.

12. Sebestain S. Congenital short pancreas. Trop Gastroenterol. 2012;33(4): 283-5.

13. Bretagne JF, Darnault P, Raoul JL, Gandon Y, Gosselin M, Cousin P, Gastard J. Calcifying pancreatitis of a congenital short pancreas: a case report with successful endoscopic papillotomy. Am J Gastroenterol. 1987;82(12):1314-7.

14. Shimodaira M, Kumagai N, Sorimachi E, Hara M, Honda K. Agenesis of the dorsal pancreas: a rare cause of diabetes. Intern Emerg Med. 2012;7(1):83-4.

15. Liang K, Ou X, Huang X, Lan Q. Agenesis of the dorsal pancreas: a rare cause of insulin-dependent diabetes without abdominal pain: case report. Medicine (Baltimore). 2018;97(9):e46.

16. Nassif S, Ponchiardi C, Sachs T. Pancreatic neuroendocrine tumor in the setting of dorsal agenesis of the pancreas. Case Rep Gastrointest Med. 2016; 2016:3801962.

17. Erotokritou A, Gerharz CD, Sagir A. Agenesis of dorsal pancreas associated with pancreatic neuroendocrine tumor: a case report and review of the literature. J Med Case Rep. 2018;12(1):185.

18. Suh PS, Lee JH, Yu JS, Hee KJ, Kim B, Kim HJ, Huh J, Kim JK, Lee D. Three cases of pancreatic pseudocysts associated with dorsal pancreatic agenesis. Radiol Case Rep. 2019;14(1):79-82.

19. Demir MK, Furuncuoglu Y. Coincidence of Polysplenia, Kartagener syndrome, dorsal pancreas agenesis, and polycystic kidney disease in an adult. Eurasian J Med. 2017:49(2):152-4.

20. Jeong JH, Kim GH, Song GA, Lee DG, Moon JY, Cheong JH, Kim S. Polysplenia syndrome with congenital agenesis of dorsal pancreas presenting as acute pancreatitis and the role of endoscopic ultrasonography in its diagnosis. Korean J Gastroenterol. 2012;60(1):47-51.

21. Macari M, Giovanniello G, Blair L, Krinsky G. Diagnosis of agenesis of the dorsal pancreas with MR pancreatography. AJR Am J Roentgenol. 1998; 170(1):144-6.
22. Pasaoglu L, Vural M, Hatipoglu HG, Tereklioglu G, Koparal S. Agenesis of the dorsal pancreas. World J Gastroenterol. 2008;14(18):2915-6.

23. Winter WE, Maclaren NK, Riley WJ, Toskes PP, Andres J, Rosenbloom AL. Congenital pancreatic hypoplasia: a syndrome of exocrine and endocrine pancreatic insufficiency. J Pediatr. 1986;109(3):465-8.

24. Oyachi N, Ohhama Y, Take H, Fukuzato Y, Murakami T, Kitagawa N, Kudo H. Aplasia of the dorsal pancreas and choledochal cyst. Pediatr Surg Int. 2006; 22(6):557-9.

\section{Publisher's Note}

Springer Nature remains neutral with regard to jurisdictional claims in published maps and institutional affiliations.

\section{Ready to submit your research? Choose BMC and benefit from:}

- fast, convenient online submission

- thorough peer review by experienced researchers in your field

- rapid publication on acceptance

- support for research data, including large and complex data types

- gold Open Access which fosters wider collaboration and increased citations

- maximum visibility for your research: over $100 \mathrm{M}$ website views per year

At $\mathrm{BMC}$, research is always in progress.

Learn more biomedcentral.com/submissions 